\title{
Decision making on unsafe abortions in Sri Lanka: a case-control study
}

\author{
Carukshi Arambepola ${ }^{* *}$ and Lalini C Rajapaksa ${ }^{2}$
}

\begin{abstract}
Background: Following an unintended pregnancy, not every woman would invariably choose to undergo an unsafe abortion. It suggests that in the decision making process, women face both 'push' factors that favour abortion and 'pull' factors that work against it. This study assessed the circumstances that surrounded a woman's decision to undergo an unsafe abortion, compared to a decision to continue, when faced with an unintended pregnancy in Sri Lanka.
\end{abstract}

Methods: An unmatched case-control study was conducted among 171 women admitted to nine hospitals in eight districts following an unsafe abortion (Cases) and 600 women admitted to the same hospitals for delivery of an unintended term pregnancy (Controls). Interviewer-administered-questionnaires and in-depth interviews assessed women's characteristics, decision making process and underlying reasons for their decision. The risk of abortion related to their decision making was assessed using odds ratio (OR) and 95\% confidence interval (CI).

Results: Compared to controls, the cases were significantly less-educated, employed, unmarried and primi-gravid $(p<0.05)$. All knew the 'illegal' status of abortion, mainly through media (65.5\% cases versus $80 \%$ controls). When making a decision, the risk of undergoing an unsafe abortion was significant among those who sought assistance (44\% versus 32\%; $\mathrm{OR}=1.7(95 \% \mathrm{Cl}=1.2-2.4)$ ), with more reliance placed on non-medical sources such as spouse/ partner, friend, neighbour and family/relation. Speaking to women with past experience of induced abortions (31\% versus 21.5\%; $\mathrm{OR}=1.6(1.1-2.4)$ and failure in making the final decision with partners also imparted a significant risk for abortion (64\% versus 34\%; $O R=3.4 ; 2.4-4.8$ ). A decision favouring unsafe abortion was predominantly based on their economic instability (29.5\%) and poor support by partners (14\%), whereas a decision against it was based on ethical considerations (44\% religious beliefs: $12 \%$ social stigma) over its legal implications (4\%). Most abortions were performed by unqualified persons (36.1\% self proclaimed abortionists; $26.2 \%$ not revealed their qualifications) for a wide range of payment in non-sterile environments (45.9\% unknown place) using septic procedures (38.5\% trans-vaginal insertions; $24.6 \%$ unaware of the procedure).

Conclusions: Women's risk of unsafe abortion was associated with unreliable sources of information during decision making that led to poor knowledge and positive attitudes on its safety; poor access to affordable abortion services; and their economic instability.

Keywords: Decision making, Unsafe abortion, Circumstances, Access and availability

\section{Introduction}

In 1995, 45.5 million abortions that took place worldwide were considered illegally induced. Concerned by this trend, many countries liberalized their laws to increase the women's access to safe abortion. By 2003, illegally induced abortions were reduced to 42 million in the world. This

\footnotetext{
* Correspondence: carukshi@yahoo.com

${ }^{1}$ Department of Community Medicine, University of Colombo, Kynsey Road, Colombo 8, Sri Lanka

Full list of author information is available at the end of the article
}

declining trend of induced abortions was more or less similar in the developed countries, where abortion was legal and easily accessible, and developing countries, where it was predominantly illegal and restricted. However, there was a striking difference noted in relation to their safety, with $55 \%$ of all induced abortions being 'unsafe' in the developing countries, compared to a much less proportion in the developed countries $[1,2]$.

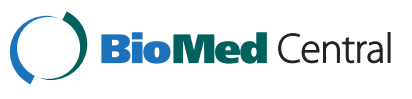


An unsafe abortion is defined as 'a procedure for terminating an unintended pregnancy either by individuals without the necessary skills or in an environment that does not conform to minimum medical standards or both' [3]. It leads to acute life-threatening as well as long-term disabling morbidity. Approximately 68,000 die from complications following unsafe abortions each year, giving a median mortality ratio of 34 per 100,000 live births in countries where abortion is illegal [4]. Consequences of such abortions are crucial in Asia, where it is concentrated among the poor, with a higher tendency towards severe complications [1]. It emphasises the need to prevent unsafe abortions among women facing an unintended pregnancy.

In Sri Lanka - a country in South Asia, with the expansion of its national family planning programme, a steady increase in the use of contraceptives has been noted from $32 \%$ in 1975 to $68 \%$ by $2006-7$ among women in the reproductive age [5]. Despite this success, induced abortion remains a commonly practised fertility control method at the rate of 45 per 1000 women in the reproductive age (95\% CI: 38-52) [6]. This rate is an indication of its growing demand although abortion is illegal in Sri Lanka. Despite being the most easily preventable cause [7], unsafe abortions is contributing considerably to the maternal morbidity and mortality in Sri Lanka, without showing a declining trend over the past few years [5]. In this backdrop, providing targeted interventions to women vulnerable to unsafe abortions would be of immense value.

Women perceive that many factors related to their socio-economic circumstances, fertility intentions, knowledge and attitudes on abortion, partner preferences, and availability and access to abortion services 'push' them towards an abortion [8-11]. These factors are populationspecific and vary based on the legal, cultural and socioeconomic background of a country. In Sri Lanka, past studies have implied poverty, poor knowledge and varying attitudes on abortion among women who seek abortion [12-14]. However, these findings may not be applicable in today's context, since the fertility aspirations of modern Asian women have drastically changed over time.

Worldwide, 25\% of unintended pregnancies end up as 'unwanted or mistimed child births' [15], highlighting that not every woman would invariably opt to undergo an abortion. More importantly, it further suggests that in addition to many 'push' factors that favour abortion, women also have 'pull' factors that work against abortion. All these factors during the decision making would determine a woman's vulnerability to abortion. Although many factors favouring induced abortion have been identified among abortion seekers [16], their risk compared to women who decide against an induced abortion has not been evaluated. Identifying the risk of these factors would empower women to make the right choice through modification of the circumstances under which they make their decisions. This would be most crucial especially for women who would decide to undergo an unsafe abortion. Thus, this study intended to assess the risk of circumstances that surrounded women who decided to undergo an unsafe abortion, compared to women who decided to carry an unintended pregnancy to term.

\section{Methods}

We carried out an unmatched case-control study including a qualitative component in nine hospitals in eight out of the 24 districts in Sri Lanka. Five of these hospitals were selected based on the highest frequency of all types of abortions reported in the Indoor Morbidity and Mortality Registers for each district [Medical Statistics Unit, unpublished]. Two hospitals were intentionally selected to ensure the representation of Muslim and estate-sectorTamil populations. In the district of Colombo, both apexreferral tertiary hospitals for women were included.

Cases were women in the selected hospitals with complications following an unsafe abortion. Controls were mothers in postnatal wards following the delivery of an unintended pregnancy carried to term. The required minimum sample was based on $80 \%$ power to detect potential associations between the cases and controls at 5\% alpha error; $20 \%$ minimum probability of exposure in the controls; odds ratio (OR) of 2; and 1:4 unmatched casecontrol ratio.

During recruitment, all women admitted to the gynaecology and medical/surgical casualty wards were screened consecutively over a period of six months for signs and symptoms suggestive of an abortion (e.g. period of amenorrhoea accompanied by vaginal bleeding, discharge, abdominal pain, fever or irregular menstruation). Of them, the potential 'cases' were identified by a confirmed diagnosis of 'induced abortion' based on the World Health Organization (WHO) criteria [17] under three categories: 'certainly induced,' probably induced' and 'possibly induced' abortion. Of these women, all 'certainly induced' abortion cases $(\mathrm{N}=122)$ and only the women who showed definitive clinical signs of infection plus received intravenous antibiotic treatment in the 'probably induced' abortion category $(\mathrm{N}=49)$ were recruited as 'cases' for the study. This restriction ensured that the group of cases represented only the women who underwent an unsafe abortion.

For comparison, controls were selected during the same study period using a systematic sampling method among mothers admitted to postnatal wards of the same hospitals following the delivery of an unintended pregnancy carried to term. 'Unintended pregnancy' was identified using an interviewer-administered-questionnaire based on the WHO definition of any pregnancy of a woman contracepting during the cycle of conception or 
not contracepting due to reasons other than desired pregnancy' [17].

Core questionnaire developed by the WHO for multicentre hospital-based descriptive studies on abortions [17] was used for data collection. It was modified to suit the local conditions and its judgmental validity (face, content and consensual) was assessed by a panel of experts in maternal health care, public health and clinical psychology. It was administered by pre-intern medical officers who were not involved in providing care in the ward. Prior to data collection, they were trained by a group of psychologists and experts in qualitative research. Using the validated questionnaire, data were collected on demographic, socio-economic and reproductive characteristics, and on decision making (the process and reasons leading to pregnancy outcomes). Circumstantial details on pregnancy termination were obtained only from the 'certainly induced' abortion cases $(\mathrm{N}=122)$. Furthermore, in-depth interviews were conducted by the principal investigator in a sub-sample of women $(\mathrm{N}=13)$ to explore their decision making process. This sample size was decided by the point of saturation at which no new information was generated. Ethics clearance was obtained for the study from the Ethics Review Committee of the Faculty of Medicine, University of Colombo.

Data were analysed using Statistical Package for Social Sciences (SPSS)-Version 20. Descriptive statistics included proportions calculated for categorical data and mean and standard deviation for quantitative data. The risk of abortion associated with women's socio-economic characteristics and their decision making was assessed by comparing the cases and controls using odds ratio (OR) and 95\% confidence intervals (CI).

\section{Results}

Of the 822 potentially induced abortions that were initially identified, 171 were recruited as cases for the study. The controls consisted of 600 post-partum mothers. There were two controls who had previously undergone an induced abortion and two cases who had done it for the second time.

The majority of women in both groups belonged to 25-29 age group, were married and of Sinhala-Buddhist origin. Compared to the controls, the significant characteristics of cases were being unmarried, primigravid, not having an informed decision on family size, less-educated, employed, having children and having longer last birth intervals (Table 1). Of the employed, more cases were in elementary occupations as manual labourers (39\% cases versus $36 \%$ controls) or as plant/machine operators (34\% versus $16 \%$ ). The non-primi gravid women were at significant risk for unsafe abortion, if they had longer average birth intervals (3.4 vs. 2.9 years) and longer last birth intervals (5.7 vs. 4.8 years).
Nearly $50 \%$ of the partners of both cases and controls had completed their upper secondary education, while nearly all were in employment. Cases differed significantly from their partners who were more educated and employed in better-skilled occupations than them $(\mathrm{p}<0.05)$. No such difference was seen between the controls and their partners.

Prior to their unintended pregnancy, all women in both groups had heard about induced abortion 'as a method of pregnancy termination' and its 'illegal' status. It was mainly through television and women newspapers (65.5\% cases versus $80 \%$ controls) and to a lesser extent from immediate associates such as friends $(14.6 \%$ versus $4.5 \%)$, neighbours $(9.9 \%$ versus $11.7 \%)$ and family/relations (5.9\% versus $5 \%$ ).

When arriving at a decision about their pregnancy (Table 2), compared to the controls, a significant proportion of cases sought advice from others (44\% cases versus $32 \%$ controls; $\mathrm{p}<0.05$ ), with more reliance placed on non-medical sources such as their spouse/partner, friend, neighbour and family/relation, and also from women who had previously undergone induced abortion ( $31 \%$ versus $21.5 \% ; \mathrm{p}<0.05$ ). In the qualitative enquiry, cases revealed that their unwillingness to approach qualified persons was due to the illegal status of abortion, while some admitted to have relied on abortion experiences of others since they had not received any formal education on abortion before.

Although women relied on partners during decision making, a higher proportion of cases made their final decision on abortion all by themselves, compared to the controls (63.7\% versus $34.2 \%)$.

Remarkably, $12.3 \%$ of the cases initially considered continuing with their pregnancy, while $42.7 \%$ of the controls considered undergoing an abortion. The commonest reason given by cases for terminating their pregnancy was not being economically stable (Table 3 ). Other reasons included poor support from the partner, too old for carrying a pregnancy and too short last birth interval. The commonest underlying reason given by controls for continuing with the pregnancy was due to religious beliefs that portrayed abortion as a 'sin'. In $12 \%$ of controls, it was due to cultural constraints that portrayed abortion as a socially unacceptable event. Good support from the partner, being economically stable and not having a short last birth interval also helped them in their decision.

After making their decision to abort, the majority of cases approached their partners and/or immediate associates to obtain more information about the persons/places available for pregnancy termination $(60 \%)$ and to accompany them to abortionists (52\%) (Table 4). It was revealed in the qualitative enquiry that in their absence, women depended on unknown sources such as taxi drivers for this purpose. 
Table 1 Risk of unsafe abortion in relation to the socio-economic status of women at the time of unintended pregnancy

\begin{tabular}{|c|c|c|c|c|c|}
\hline \multirow{3}{*}{ Characteristic } & \multirow{2}{*}{\multicolumn{2}{|c|}{$\begin{array}{c}\text { Cases } \\
\mathrm{N}=171 *\end{array}$}} & \multirow{2}{*}{\multicolumn{2}{|c|}{$\begin{array}{l}\text { Controls } \\
\mathrm{N}=600^{*}\end{array}$}} & \multirow{3}{*}{$\begin{array}{c}\text { Odds ratio } \\
(95 \% \mathrm{Cl})\end{array}$} \\
\hline & & & & & \\
\hline & No. & $\%$ & No. & $\%$ & \\
\hline \multicolumn{6}{|l|}{ Current marital status } \\
\hline Single/divorce/separate/widow & 31 & $18.1 \%$ & 10 & $1.7 \%$ & $12.9(6.3-27)$ \\
\hline \multicolumn{6}{|l|}{ Parity (P) } \\
\hline Primi & 36 & $21.1 \%$ & 83 & $13.8 \%$ & $1.7(1.1-2.6)$ \\
\hline \multicolumn{6}{|l|}{ Decided on family size } \\
\hline No & 89 & $52.0 \%$ & 173 & $28.8 \%$ & $2.7(1.9-3.8)$ \\
\hline \multicolumn{6}{|l|}{ On contraceptives } \\
\hline No & 103 & $60.2 \%$ & 238 & $39.7 \%$ & $1.5(0.9-2.2)$ \\
\hline \multicolumn{6}{|l|}{ Living children } \\
\hline Yes & 40 & $23.4 \%$ & 92 & $15.3 \%$ & $1.7(1.1-2.6)$ \\
\hline \multicolumn{6}{|l|}{ Secondary education } \\
\hline Not completed & 115 & $67.6 \%$ & 332 & $55.5 \%$ & $1.7(1.2-2.4)$ \\
\hline \multicolumn{6}{|l|}{ Currently employed } \\
\hline Yes & 69 & $40.4 \%$ & 149 & $24.8 \%$ & $2.1(1.4-2.9)$ \\
\hline \multicolumn{6}{|l|}{ Type of occupation ${ }^{1}$} \\
\hline Unskilled/Less skilled & 52 & $76.5 \%$ & 80 & $56.3 \%$ & $2.5(1.3-4.8)$ \\
\hline \multicolumn{6}{|l|}{ Secondary education of partner } \\
\hline Not completed & 89 & $59.7 \%$ & 308 & $52.1 \%$ & $1.4(0.7-1.6)$ \\
\hline
\end{tabular}

*In some variables, row values do not add up to the total cases and controls due to missing data.

${ }^{1}$ Includes only the employed women.

$\mathrm{Cl}=$ confidence interval.

Table 2 Risk of unsafe abortion in relation to the decision making process among women with unintended pregnancies

\begin{tabular}{|c|c|c|c|c|c|}
\hline \multirow[t]{2}{*}{ Decision making process } & \multicolumn{2}{|c|}{$\begin{array}{c}\text { Cases } \\
\mathrm{N}=171\end{array}$} & \multicolumn{2}{|c|}{$\begin{array}{l}\text { Controls } \\
\mathrm{N}=600\end{array}$} & \multirow[t]{2}{*}{$\begin{array}{l}\text { Odds ratio } \\
(95 \% \mathrm{Cl})\end{array}$} \\
\hline & No. & $\%$ & No. & $\%$ & \\
\hline \multicolumn{6}{|c|}{ Advice sought at decision making } \\
\hline Yes $^{*}$ & 76 & $44.4 \%$ & 190 & $31.7 \%$ & $1.7(1.2-2.4)$ \\
\hline - Friend & 38 & $22.2 \%$ & 26 & $4.3 \%$ & \\
\hline - Family/Relation & 30 & $17.5 \%$ & 12 & $2.0 \%$ & \\
\hline - Neighbour & 6 & $3.5 \%$ & 8 & $1.3 \%$ & \\
\hline - Medical personnel & 0 & $0.0 \%$ & 10 & $1.7 \%$ & \\
\hline - Spouse/ Partner & 62 & $36.6 \%$ & 171 & $28.5 \%$ & \\
\hline \multicolumn{6}{|c|}{ Final decision made with partner } \\
\hline No & 109 & $63.7 \%$ & 205 & $34.2 \%$ & $3.4(2.4-4.8)$ \\
\hline \multicolumn{6}{|c|}{ Spoken to a person who had experienced an abortion } \\
\hline Yes & 53 & $31.0 \%$ & 129 & $21.5 \%$ & $1.6(1.1-2.4)$ \\
\hline \multicolumn{6}{|c|}{ Will undergo abortion if any unintended pregnancy in future } \\
\hline Yes & 17 & $9.9 \%$ & 7 & $1.2 \%$ & $19.7(7.8-50.1)$ \\
\hline Difficult to say & 58 & $33.9 \%$ & 211 & $35.2 \%$ & $2.2(1.5-3.4)$ \\
\hline
\end{tabular}

${ }^{*}$ Multiple responses; sources of information do not add to the total who took advice.

$\mathrm{Cl}=$ confidence interval. 
Table 3 Comparison of the underlying reasons for undergoing abortion/continuing with the pregnancy between the cases $(\mathrm{N}=122)$ and controls $(\mathrm{N}=600)$

\begin{tabular}{|c|c|c|c|c|c|}
\hline \multirow{2}{*}{$\begin{array}{l}\text { Underlying reasons for } \\
\text { undergoing induced } \\
\text { abortion }\end{array}$} & \multicolumn{2}{|c|}{ Cases } & \multirow{2}{*}{$\begin{array}{l}\text { Underlying reasons for } \\
\text { continuing with pregnancy }\end{array}$} & \multicolumn{2}{|c|}{ Controls } \\
\hline & No. & $\%^{1}$ & & No. & $\%^{1}$ \\
\hline Economically not stable & 36 & $29.5 \%$ & Religious beliefs on abortion & 266 & $44.3 \%$ \\
\hline Partner advocates abortion & 17 & $13.9 \%$ & Partner supports pregnancy & 167 & $27.8 \%$ \\
\hline Too old for a pregnancy & 14 & $11.5 \%$ & Economically stable & 74 & $12.3 \%$ \\
\hline Last birth interval too short & 13 & $10.7 \%$ & Social stigma attached to abortion & 73 & $12.2 \%$ \\
\hline Unmarried status/ Widowhood & 10 & $8.2 \%$ & Last birth interval not too short & 50 & $8.3 \%$ \\
\hline Extra-marital affair & 9 & $7.4 \%$ & Forced by health worker & 28 & $4.7 \%$ \\
\hline Plans to go for a job & 6 & $4.9 \%$ & Illegal status of abortion & 25 & $4.2 \%$ \\
\hline Not ready for motherhood & 5 & $4.1 \%$ & Did not know how to get it aborted & 23 & $3.8 \%$ \\
\hline Rape & 5 & $4.1 \%$ & Forced by partner, family or friends & 21 & $3.5 \%$ \\
\hline Forced by partner & 4 & $3.3 \%$ & Others know I am pregnant & 6 & $1.0 \%$ \\
\hline Female foetus on scan & 1 & $0.8 \%$ & After visualizing the foetus on scan & 1 & $0.2 \%$ \\
\hline
\end{tabular}

*Women who admitted to have undergone an unsafe abortion were only included in the analysis.

${ }^{1}$ Multiple responses; percentages given out of the total in cases or controls.

Only $11 \%$ of cases attempted methods of self-induction. $46 \%$ of cases visited the abortionist more than twice and $14 \%$ more than five times. In the majority of cases, septic procedures with no pain relief were performed during termination by non-qualified abortionists, for a wide range of payment of Rs. 1,000-30,000. In the qualitative inquiry, women reported that most places lacked sterile or proper equipment and were run without assistance in the back room of a boutique, own home or in the house of a relative or abortionist. None took place in government hospitals or clinics run by non-governmental organizations. The most commonly used methods were trans-vaginal insertion of rods and injections. The worst experience reported in the qualitative inquiry was one woman collapsing following the insertion of a castor oil plant stem into the vagina for a fee of Rs. 30,000. In response to future intentions, $14 \%$ of cases alleged that they would resort to abortion in the event of another unwanted pregnancy, while $47.5 \%$ were not sure of their decision.

\section{Discussion}

This study sheds light on the decision making process and circumstances leading to an unsafe abortion, in comparison with that leading to a mistimed birth, in a setting where abortion is illegal. It should be noted that these findings are not applicable to women who succeeded a safely induced abortion, but to those who developed complications following an unsafe abortion. Thus, this study is unique, providing evidence on the women who are most vulnerable to maternal morbidity and mortality.

Health status of Sri Lanka is sustained by the Government policy of 'free health for all' that has been instrumental in achieving a high health literacy and health seeking behaviour, especially among the females [5]. Our findings however are contrary to the expected, highlighting deficiencies in the provision of information to women on the health implications of unsafe abortion and women's utilisation of unsafe abortion services. In comparison, previous studies have shown that women face difficulties in obtaining both information and services on abortion in low-resource and low-literacy settings, irrespective of the legal status of abortion $[11,14,18]$.

\section{The role of access to information in the decision making}

Our study shows that a decision to abort using unsafe techniques is significantly associated with the risk of women seeking access to information about its safety during the decision making process (44\% cases versus $32 \%$ controls). Furthermore, in the absence of any formal channel providing awareness, cases seemed to rely more than their controls on non-medical sources for knowledge. Despite the free health service that ensures access to state-owned health facilities throughout the country [5], the reluctance of women to approach a healthcare worker in the event of an unintended pregnancy, was probably due to the illegal status of abortion in Sri Lanka. Stigma attached to abortion could also be a major deterrent $[11,18]$. With the wide accessibility of mobile telecommunication services even in the most remote areas in Sri Lanka, exploring the possibility of establishing 24-hour help lines for reliable information at the community level would be of much value [19]. Abortion education through media did not play a significant role in the decision making in our study. Nevertheless, close monitoring of any sensationalising abortion news by media is highly recommended. Furthermore, to prevent the vulnerable groups being misinformed, women need to be empowered with knowledge on the safety of abortion 
Table 4 Characteristics of the termination of pregnancy among women who underwent certainly induced abortion $(\mathrm{N}=122)^{1}$

\begin{tabular}{|c|c|c|}
\hline Characteristic & No. & $\%$ \\
\hline \multicolumn{3}{|l|}{ Sought help on ways to terminate the pregnancy } \\
\hline Did not seek help & 49 & $40.2 \%$ \\
\hline \multicolumn{3}{|l|}{ Sought help } \\
\hline - Husband/Partner & 37 & $30.3 \%$ \\
\hline - Family/Relative & 10 & $8.2 \%$ \\
\hline • Friend/ Neighbour & 27 & $22.1 \%$ \\
\hline - Medical person & 1 & $0.8 \%$ \\
\hline - Three wheel Taxi drivers & 3 & $2.5 \%$ \\
\hline \multicolumn{3}{|l|}{ Person who did the abortion } \\
\hline Qualified doctor & 25 & $20.5 \%$ \\
\hline Traditional healer & 3 & $2.5 \%$ \\
\hline Pharmacist & 2 & $1.6 \%$ \\
\hline On her own without any help & 13 & $10.7 \%$ \\
\hline Other (Friend/Husband/Family member) & 3 & $2.5 \%$ \\
\hline Self proclaimed abortionists & 44 & $36.1 \%$ \\
\hline Ignorant of his status/No response ${ }^{2}$ & 32 & $26.2 \%$ \\
\hline \multicolumn{3}{|l|}{ Delay since termination to reach the hospital } \\
\hline Within a day & 13 & $10.7 \%$ \\
\hline 2-4 days & 26 & $21.3 \%$ \\
\hline 5-7 days & 18 & $14.8 \%$ \\
\hline More than one week & 24 & $19.7 \%$ \\
\hline Not sure/No response ${ }^{2}$ & 41 & $33.6 \%$ \\
\hline \multicolumn{3}{|l|}{ Method used for termination of pregnancy } \\
\hline Trans-vaginal insertion & 47 & $38.5 \%$ \\
\hline Injections & 7 & $5.7 \%$ \\
\hline Indigenous medicine and tonic & 16 & $13.1 \%$ \\
\hline Abdominal or trans-vaginal application of pressure & 7 & $5.7 \%$ \\
\hline Vacuum aspiration & 9 & $7.4 \%$ \\
\hline Dilatation and curettage & 1 & $0.8 \%$ \\
\hline Medicine (E.g. Misoprostol) & 5 & $4.1 \%$ \\
\hline Ignorant of the procedure/No response $\mathrm{e}^{2,3}$ & 30 & $24.6 \%$ \\
\hline \multicolumn{3}{|l|}{ Place of abortion } \\
\hline Private hospital & 8 & $6.6 \%$ \\
\hline GP Practice & 14 & $11.5 \%$ \\
\hline Own home/Friend's house & 7 & $5.7 \%$ \\
\hline Unknown place (E.g. Abortionist's house, boutique) & 56 & $45.9 \%$ \\
\hline Ignorant of the place/No response ${ }^{2}$ & 37 & $30.3 \%$ \\
\hline \multicolumn{3}{|l|}{$\begin{array}{l}\text { Persons who accompanied the woman } \\
\text { for the abortion }\end{array}$} \\
\hline Husband/Partner & 41 & $33.6 \%$ \\
\hline Friend & 10 & $8.2 \%$ \\
\hline
\end{tabular}

Table 4 Characteristics of the termination of pregnancy among women who underwent certainly induced abortion ( $\mathbf{N}=\mathbf{1 2 2})^{1}$ (Continued)

\begin{tabular}{lcc}
\hline Sibling/relation & 12 & $9.8 \%$ \\
None & 21 & $17.2 \%$ \\
No response 2,4 & 38 & $31.1 \%$ \\
Total & 122 & $\mathbf{1 0 0 . 0 \%}$ \\
\hline${ }^{1}$ Women who admitted to have undergone an unsafe abortion were only \\
included in the analysis. \\
${ }^{2}$ Includes women who were reluctant to reveal the information. \\
${ }^{3}$ Also includes respondents who were not sure of the method used. \\
${ }^{4}$ Also includes 13 women who attempted termination by themselves.
\end{tabular}

from an early age. Adolescence would be the ideal time to approach them through educational opportunities such as school-based internet inquiry [20,21]. Though sexual health is already a vital component in the school curriculum, there may be cultural barriers in discussing these topics at school. It is thus important to provide skill development for teachers.

Previous research has implied varying attitudes on unsafe abortion among women who seek abortion $[1,14,18,22]$. Our study implies that the risk of unsafe abortion associated with access to unreliable non-medical sources of information is not only because it leads to poor knowledge on its safety but also because it formulates positive attitudes towards induction. Close associates seemed to play a crucial role in changing women's perceptions on abortion as a 'safe' procedure. In particular, women showed a tendency to confide more in other women's experience of successful inductions. This type of 'herd behaviour' was probably facilitated by their low socio-economic status characterised by low level of education and employment in unskilled/semi-skilled occupations. The equally low social status of their co-workers seems to reinforce the women's poor access to correct information as well as to safer abortion services. It is shown that unlike home-bound women, employed women are more at risk for unsafe abortions, with many opportunities for clandestine sexual relationships and peer influences [23]. Therefore, multi-pronged interventions in the form of counselling services should take priority in these high-risk settings. With high literacy among women in Sri Lanka, work settings could be equipped with educational material and contraceptives. Evidence recommends behaviour change communication campaigns through inter-personal approaches that engage community leaders and influencers [18], dialogue-based groups that negotiate the social support they need when making decisions [24] and community intermediaries that create an enabling environment [25] as feasible methods.

In previous studies in Asia, a significant decision maker has been the partner with their direct involvement through "orders" to abort or indirectly through denial of 
responsibility for the pregnancy $[11,26]$. Our findings are in contrast to this, highlighting the changing women status in Asia. Although partners of cases were of better socio-economic status than of their controls, partners' influence seemed to be minimal when making the final decision to abort a pregnancy. However, once the decision was made, men were utilised more by cases to accompany them to abortionists.

\section{The role of safe abortion services in the decision making}

Increased availability as well as accessibility have shown to improve the quality of induced abortions in countries where abortion is legalised $[22,27,28]$. Our study verifies that the vulnerability of Sri Lankan women to unsafe abortion is mainly due to poor access to affordable abortion services. This was explicit, with an increased risk of unsafe abortion seen among women of low socio-economic status. It is alleged that safe abortion services are not uncommon in the country, but almost always offered for a substantial fee. This is in contrast to the health seeking behaviour in the past, during which 'menstrual regulation methods' were offered to clients for an affordable fee by a few non-governmental organizations [29].

\section{Circumstances leading to unsafe abortion}

Worldwide, the commonly reported reasons for unsafe abortion are postponement or completion of child-bearing and socio-economic concerns such as poverty and unemployment $[10,29,30]$. However, a recent study concluded that a decision to undergo abortion is typically motivated by multiple, diverse and inter-related reasons on financial constraints and lack of partner support [31]. These factors coincide well with our findings, which confirm that a decision favouring unsafe abortion was predominantly based on their economic instability and poor support given by partners.

Other than the 'push' factors, several 'pull' factors that prevent a decision of abortion were also identified in our study. Sri Lanka is a multi-ethnic country with strong religious convictions. In a local study among women, $94 \%$ felt that abortion was a 'sin' while $66 \%$ felt that it should be available on demand for married women [12]. It is interesting to note that women who decided against abortion considered more about the ethical aspect (44.3\% religious beliefs: $12.2 \%$ social stigma) than its legal status. This implies that even if abortion is legalised, safe abortion services would remain under-utilised, unless the stigma attached to abortions that leads to the reluctance of both women accessing the services and the health care staff providing it, is addressed. Under-utilisation of safe abortion services due to poor knowledge [18], religious beliefs $[32,33]$ and stigma $[14,34]$ has been observed elsewhere. Holmgren \& Uddenberg [32] have reported that women's main moral dilemma was not a conflict between the woman and her foetus, but a conflict between several close relationships, also concerning the prospective father [32]. It is imperative that health managers ensure that clients' information against unauthorised disclosure is protected by creating a respectful environment, with physical space for assuring privacy, a wide-range of skills for building rapport with women in a culturally-attuned empathic manner and attitudinal changes at all levels of health care providers to treat them with dignity, so that women are comfortable in discussing their decision making with health staff. Sri Lanka Government health policy aims to facilitate equity through increased access to health services and quality of care.

\section{Methods of abortion}

Circumstances under which most of the unsafe abortions took place illustrate the extremely poor quality of the services provided by Abortionists. Most were done by unqualified persons for a wide range of payment in unsterile environments using septic procedures. It is evident from our study that the procedures used by abortionists had been more or less similar, compared to the methods used on abortion cases in hospitals a few decades ago $[29,35]$. Legal enforcement of severe punishment to these unqualified abortionists would be effective. This would prevent the less resourced districts to have access to unsafe abortion services. Decisions to refer or to keep in their care by abortionists are strongly associated with the patients' financial resources [36]. In our study too, women's health seeking behaviour following an unsafe abortion was determined by the advice provided by the abortionist; poorer women to visit the hospital immediately and others to be treated in a private hospital.

\section{Limitations}

Our sample has not captured the women who sought care outside Government hospitals following postabortion complications. This could have led to an overrepresentation of cases of poor socio-economic status, since the state owned health services are free of charge and thus, predominantly accessed by people of relatively low socio-economic status. However, this selection bias was minimised by having controls accessing the same hospital services $\mathrm{s}$ as the cases.

\section{Conclusions}

A decision favouring unsafe abortion was predominantly based on their economic instability and poor support given by partners, whereas a decision against it was based on ethical considerations over its legal implications. Reliance on non-medical sources of information such as immediate associates leading to poor knowledge as well as positive attitudes on its safety played a crucial role in the decision making process towards an unsafe 
abortion. Unsafe methods of termination used have not changed over time. It is believed that the findings of this study would also be applicable to similar settings in developing countries.

\section{Competing interests}

The authors declare that they have no competing interests.

\section{Authors' contributions}

CA was the principal investigator of the study. CA,LCR have made substantial contributions to conception and design, acquisition of data, analysis and interpretation of data. CA has been involved in drafting the manuscript or revising it critically for important intellectual content. LCR has given final approval of the version to be published. CA, LCR agree to be accountable for all aspects of the work in ensuring that questions related to the accuracy or integrity of any part of the work are appropriately investigated and resolved. All authors read and approved the final manuscript.

\section{Acknowledgement}

We acknowledge the financial assistance granted by the United Nations Population Fund (UNFPA), Bauddhaloka Mawatha, Colombo 7, Sri Lanka for conducting this research. We are also grateful to the Provincial Directors of Health Services (PDHS) and Directors of the hospitals for giving us permission to collect data.

\section{Author details}

${ }^{1}$ Department of Community Medicine, University of Colombo, Kynsey Road, Colombo 8, Sri Lanka. ${ }^{2}$ Former Professor in Community Medicine, University of Colombo, Kynsey Road, Colombo 8, Sri Lanka.

Received: 21 June 2014 Accepted: 10 December 2014 Published: 17 December 2014

\section{References}

1. Grimes DA, Benson J, Singh S, Romero M, Ganatra B, Okonofua FE, Shah $\mathbb{H}$ : Unsafe abortion: the preventable pandemic. Lancet 2006, 368(9550):1908-1919.

2. Sedgh $G$, Henshaw S, Singh S, Åhman E, Shah IH: Induced abortion: estimated rates and trends worldwide. Lancet 2007, 370(9595):1338-1345.

3. World Health Organization: The prevention and management of unsafe abortion. Report of aTechnical Working Group. Geneva: 1992.

4. Haddad LB, Nawal MN: Unsafe abortion: unnecessary maternal mortality. Rev Obstet Gynecol 2009, 2(2):122.

5. Department of Census and Statistics: Sri Lanka Demographic and Health Survey 2006-07. Colombo: 2007.

6. Rajapakse L: Estimates of induced abortions in urban and rural Sri Lanka. Sri Lanka: Report of the Faculty of Medicine, University of Colombo; 2000.

7. Corbett MR, Turner KL: Essential elements of postabortion care: origins, evolution and future directions. Int Fam Plan Perspect 2003, 29(3):106-111.

8. Alex IM: Determinants of unsafe abortion in developing countries. In Preventing unsafe abortion and its consequences: priorities for Research and Action. Edited by Warriner IK, Shah IH. New York: Guttmacher Institute; 2006:51-71.

9. Bracken MB, Klerman LV, Bracken M: Abortion, adoption, or motherhood: an empirical study of decision-making during pregnancy. Am J Obstet Gynecol 1978, 130(3):251-262.

10. Sihvo S, Bajos N, Ducot B, Kaminski M: Women's life cycle and abortion decision in unintended pregnancies. J Epidemiol Community Health 2003, 57(8):601-605.

11. Tong WT, Wah YL, Yut LW, Sim PC, Ravindran J: Exploring pregnancy termination experiences and needs among Malaysian women: A qualitative study. BMC Public Health 2012, 12(1):743.

12. Rajapaksa LC, De Silva WI: Profile of Women Seeking Abortion. Sri Lanka: Report of the University of Colombo; 2000

13. Thalagala N: Process, determinants and impact of unsafe abortions in Sri Lanka. Family Planning Association of Sri Lanka: Colombo, Sri Lanka; 2010.

14. Perera J, de Silva T, Gange H: Knowledge, behaviour and attitudes on induced abortion and family planning among Sri Lankan women seeking termination of pregnancy. Ceylon Med J 2004, 49(1):14-17.
15. Gipson JD, Koenig MA, Hindin MJ: The effects of unintended pregnancy on infant, child, and parental health: a review of the literature. Stud Fam Plann 2008, 39(1):18-38.

16. Sousa A, Lozano R, Gakidou E: Exploring the determinants of unsafe abortion: improving the evidence base in Mexico. Health Policy Plan 2010, 25(4):300-310.

17. World Health Organization: Studying unsafe abortion: a practical guide. Geneva: 1996.

18. Banerjee SK, Andersen KL, Buchanan RM, Warvadekar J: Woman-centered research on access to safe abortion services and implications for behavioral change communication interventions: a cross-sectional study of women in Bihar and Jharkhand, India. BMC Public Health 2012, 12(1):175.

19. Norman W, Hestrin B: Access to complex abortion care service and planning improved through a toll-free telephone resource line. ; 2013.

20. Mitchell EMH, Silke H, Ana A, Leila A, Carolyn TH: Brazilian adolescents' knowledge and beliefs about abortion methods: a school-based internet inquiry. BMC Womens Health 2014, 14(1):27.

21. Bengtsson AM: Information needs among Italian abortion patients. Gynecol Obstet Invest 1997, 43(2):84-88.

22. Faria G, Elwin B, Goodman LM: Women and abortion: attitudes, social networks, decision-making. Soc Work Health Care 1985, 11(1):85-99.

23. Savitz DA, Whelan EA, Rowland AS, Kleckner RC: Maternal employment and reproductive risk factors. Am J Epidemiol 1990, 132(5):933-945.

24. Allison B, Drake JK, Goodyear L, Gopinath CY, Kaufman A, Bhattarai S: The role of interpersonal communication in preventing unsafe abortion in communities: the Dialogues for Life Project in Nepal. J Health Commun 2011, 16(3):245-263.

25. Banerjee SK, Andersen KL, Baird TL, Ganatra B, Batra S, Warvadekar J: Evaluation of a multi-pronged intervention to improve access to safe abortion care in two districts in Jharkhand. BMC Health Serv Res 2014, 14(1):227.

26. Schwandt HM, Creanga AA, Adanu RMK, Danso KA, Agbenyega T, Hindin MJ: Pathways to unsafe abortion in Ghana: the role of male partners, women and health care providers. Contraception 2013, 88(4):509-517.

27. Font-Ribera L, Pérez G, Salvador J, Borrell C: Socioeconomic inequalities in unintended pregnancy and abortion decision. J Urban Health 2008, 85(1):125-135.

28. Banerjee SK, Andersen K: Exploring the pathways of unsafe abortion in Madhya Pradesh, India. Glob Public Health 2012, 7(8):882-896.

29. Ban DJ, Kim JINHYUN, De Silva WI: Induced abortion in Sri Lanka: who goes to providers for pregnancy termination? J Biosoc Sci 2002, 34(3):303-316.

30. Bankole A, Singh S, Taylor H: Reasons why women have induced abortions: evidence from 27 countries. Int Fam Plan Perspect 1998, 24:117-127.

31. Finer LB, Lori FF, Lindsay AD, Singh S, Moore AM: Reasons US women have abortions: quantitative and qualitative perspectives. Perspect Sex Reprod Health 2005, 37(3):110-118.

32. Holmgren $\mathrm{K}$, Uddenberg $\mathrm{N}$ : Abortion ethics-women's post abortion assessments. Acta Obstet Gynecol Scand 1994, 73(6):492-496.

33. Onah HE, Ogbuokiri CM, Obi SN, Oguanuo TC: Knowledge, attitude and practice of private medical practitioners towards abortion and post abortion care in Enugu, south-eastern Nigeria. J Obstet Gynaecol 2009, 29(5):415-418.

34. Astbury-Ward E, Odette P, Carnwell R: Stigma, Abortion, and Disclosure-Findings from a Qualitative Study. J Sex Med 2012, 9(12):3137-3147.

35. Lane SD, Jok MJ, El-Mouelhy MT: Buying safety: the economics of reproductive risk and abortion in Egypt. Soc Sci Med 1998, 47(8):1089-1099.

36. Nathanson CA, Marshall HB: Physician behavior as a determinant of utilization patterns: the case of abortion. Am J Public Health 1978, 68(11):1104-1114.

doi:10.1186/1742-4755-11-91

Cite this article as: Arambepola and Rajapaksa: Decision making on unsafe abortions in Sri Lanka: a case-control study. Reproductive Health 2014 11:91. 